\title{
When experiment challenges theory: Scattering of vibrationally excited molecules in the cold collision energy regime
}

\author{
F. Javier Aoiz ${ }^{1}$ \\ ${ }^{1}$ University Complutense of Madrid
}

October 14, 2021

\section{Hosted file}

Aoiz_Highlight_12.10.21.pdf available at https://authorea.com/users/440975/articles/541589when-experiment-challenges-theory-scattering-of-vibrationally-excited-molecules-in-thecold-collision-energy-regime 